\title{
Hibiscus flower extract selectively induces apoptosis in breast cancer cells and positively interacts with common chemotherapeutics
}

Christopher Nguyen, Kiruthika Baskaran, Alaina Pupulin, Ivan Ruvinov, Ola Zaitoon, Sahibjot Grewal, Benjamin Scaria, Ali Mehaidli, Caleb Vegh and Siyaram Pandey ${ }^{*}$ (D)

\begin{abstract}
Background: Current therapeutic approaches to treat metastatic breast cancer, although effective, have shown many inadvertent side effects such as genotoxicity due to a lack of selectivity. Thus, these treatment plans are not suitable for long-term usage. Natural health product extracts are safe for long-term consumption and some have shown to be medicinally active containing multiple bioactive compounds able target multiple vulnerabilities in cancer. One of which, Hibiscus rosa-sinesis (hibiscus) extract, has been reported to have many medicinal and anticancer properties due to its antioxidant and hypolipidemic effects. However, its efficacy against breast cancer has not been fully investigated and characterized. If effective against cancer, hibiscus extract could potentially be combined with chemotherapeutic treatments in adjuvant therapy to reduce chemotherapy-inducing side effects.

Method: We have investigated aqueous hibiscus flower extract anticancer efficacy, selectivity, and interactions with chemotherapeutics taxol, cisplatin, and tamoxifen in estrogen-receptor positive breast cancer cells, triple-negative human breast cancer cells, and normal non-cancerous cells. Apoptotic morphology and biochemical marker expression were assessed to determine the extent anticancer efficacy of hibiscus. Mitochondrial membrane potential reduction and reactive oxygen species generation were quantified using fluorogenic dyes to determine the mechanism of hibiscus extract action.

Results: Hibiscus extract was able to selectively induce apoptosis in both triple-negative and estrogen-receptor positive breast cancer cells in a dosage-dependent manner. Most importantly, addition of hibiscus extract was found to enhance the induction of apoptosis of chemotherapy treatments (taxol and cisplatin) in triple-negative breast cancer cells when compared to treatment alone. Moreover, hibiscus extract addition to chemotherapy treatment was able to increase oxidative stress and decrease mitochondrial membrane potential compared to individual treatments.

Conclusion: Hibiscus extract is effective on breast cancer, most notably on generally resistant triple-negative breast cancer, while being selective for normal healthy cells. Hibiscus extract could supplement chemotherapeutic regimens as an adjuvant and lead to a more efficacious treatment approach to reduce chemotherapy dosages and related toxicity.
\end{abstract}

Keywords: Hibiscus, Breast cancer, Chemotherapeutic interactions, Natural health products, Adjuvant therapy, Apoptosis, Taxol, Cisplatin, Tamoxifen

\footnotetext{
* Correspondence: spandey@uwindsor.ca

Department of Chemistry and Biochemistry, University of Windsor, 401

Sunset Ave, Windsor, ON N9B 3P4, Canada
}

(c) The Author(s). 2019 Open Access This article is distributed under the terms of the Creative Commons Attribution 4.0 International License (http://creativecommons.org/licenses/by/4.0/), which permits unrestricted use, distribution, and reproduction in any medium, provided you give appropriate credit to the original author(s) and the source, provide a link to the Creative Commons license, and indicate if changes were made. The Creative Commons Public Domain Dedication waiver (http://creativecommons.org/publicdomain/zero/1.0/) applies to the data made available in this article, unless otherwise stated. 


\section{Background}

Breast cancer is the most prevalent cancer among women worldwide, accounting for $25 \%$ of cancer incidence and $15 \%$ of cancer deaths among females [1]. Current work has developed and enhanced prediction models, screening methods, diagnostic tools, and disease management [2-6]. However, breast cancer treatment approaches become more complicated once the disease progresses to the complex metastatic stage. Although surgery to remove tumours in breast cancer has a high probability of survival, the majority of breast cancer related deaths are not from the primary tumour itself, but a result of metastasis to organs [7].

Apoptosis is the complex and ordered physiological process of cell death. An understanding of cell death, particularly in relation to cancer, allows for an assessment of the pathogenesis and treatment of the disease [8]. The exploitation of cellular vulnerabilities in cancerous cells, including oxidative stress and mitochondrial membrane destabilization, by therapeutic agents could trigger apoptosis and potentially eradicate the disease $[9,10]$. Indeed, most therapeutics have been developed to induce cell death. However, many treatments are unfortunately nonspecific for cancer and can additionally target healthy non-cancerous cells eventually leading to inadvertent side effects and toxicity $[11,12]$.

Current treatments for metastatic breast cancer include adjuvant chemotherapy using cytotoxic drugs including anthracyclines, taxane-based, and platinum-based drugs [13]. Although both taxane-based and platinum-based chemotherapeutics have shown effectiveness in treating breast cancer, both drugs have exhibited toxicity and lack of selectivity to support a long-term treatment plan $[11,12]$. One study evaluating over 1000 patients found that treatments of anthracycline and taxane-based adjuvant strategies led to a higher pathologic complete response and higher survivability. However, a high risk of tumour relapse is possible if the tumour is not completely eradicated $[14,15]$. Thus, there exists a great need for a treatment that can avoid toxicity in treatments while also able to be used on a long-term basis.

Natural health products (NHPs) are materials isolated from various food and plant sources that have been shown to have medicinal properties [16]. The commonly used chemotherapeutic taxol was isolated from the bark extract of the Pacific yew tree, Taxus brevifolia, when the extract was shown to have a cytotoxic effect [17]. Although many treatments have been derived from natural sources, we have yet to exhaust nature's vast variety of selection. It is possible that a well-tolerated, highly potent anticancer compound is still left to be discovered and developed into a novel cancer therapeutic. Indeed, many NHPs have been shown to induce apoptosis selectively in cancer cells, including our research into dandelion root, lemongrass, and long pepper extracts [18-20]. Traditionally, NHPs have been used widely as both medicinal and food products [21].

Hibiscus flower (Hibiscus rosa-sinesis) has traditionally been used and has been shown to have high pharmacological potential to treat disorders such as hypertension and pyrexia [22]. Further, hibiscus extract (HE) has been shown to have significant antioxidant and hypolipidemic effects [23]. Previous work on hibiscus has indicated that HE exhibits significant anticancer efficacy on prostate cancer, leukemia, gastric cancer, and human squamous cell carcinoma [24-27]. A previous study of Hibiscus syriacus observed that several triterpenoids from $\mathrm{HE}$ were able to inhibit triple-negative breast cancer cell viability with limited toxicity on normal cells [28]. This work lends support to the notion that a whole plant extract of hibiscus could contain anticancer compounds while being well-tolerated.

Triple-negative breast cancer accounts for approximately $15-20 \%$ of all breast cancers and is characterized by negative expression of estrogen and progesterone receptors as well as HER2 protein [29]. Many challenges arise in the treatment of triple-negative breast cancer due to poor prognosis resulting from the lack of actionable targets in order to use a specific targeted therapy able to combat the disease $[30,31]$. As such, the discovery and development of therapies able to target triple-negative breast cancer is of great importance.

We aimed to investigate the efficacy of $\mathrm{HE}$ against breast cancer by assessing the toxicity of HE treatment on human triple-negative and estrogen-receptor positive $(\mathrm{ER}+)$ breast cancer cells. Further, we aimed to investigate its interaction with current chemotherapies to assess the potential of its use in adjuvant therapies.

In this study, we have shown that aqueous HE is able to induce apoptosis in breast cancer cell models in vitro in a dose-dependent manner. We have also shown that HE treatment shows selectivity for cancer cells, with minimal effect on normal non-cancerous cells. Most importantly, we wanted to investigate the potential of using $\mathrm{HE}$ as an adjuvant to current chemotherapeutic treatments. We have demonstrated HE treatments (when combined with chemotherapeutic treatments) enhanced the induction of apoptosis when compared to individual treatment alone. These results support the possibility of supplementing chemotherapeutic regimens with $\mathrm{HE}$, which has shown to be well-tolerated in normal non-cancerous cells. This may lead to a better combined effect, reducing the chemotherapeutic dosages and related toxicity.

\section{Methods}

Hibiscus leaf aqueous extraction

Hibiscus flower (Hibiscus rosa-sinensis) were obtained from Premier Herbal Inc. (Toronto, ON, Canada). This 
aqueous extraction protocol is similar to that previously published with the following modifications $[18,19]$. The flowers were grinded using a coffee grinder into a fine powder. The powder was extracted in boiled double distilled water $\left(\mathrm{ddH}_{2} \mathrm{O}\right)\left(1 \mathrm{~g}\right.$ leaf powder to $\left.10 \mathrm{~mL} \mathrm{ddH}_{2} \mathrm{O}\right)$ at $60^{\circ} \mathrm{C}$ for $3 \mathrm{~h}$. The extract was then run through a cheese cloth and then filtered via gravity filtration with a P8 coarse filter, followed by vacuum filtration with a $0.45 \mu \mathrm{m}$ filter (PALL Life Sciences, VWR, Mississauga ON, CA Cat No. 28148-028). The water extract was frozen at $-80^{\circ} \mathrm{C}$, freeze dried using a lyophilizer and then reconstituted in $\mathrm{ddH}_{2} \mathrm{O}$ in order to obtain a final stock concentration of $100 \mathrm{mg} / \mathrm{mL}$. Prior to use, the water extract was passed through a $0.22 \mu \mathrm{m}$ filter (Sarstedt, Montreal, QC, CA Cat No. 83.1826.001) in a biosafety cabinet.

\section{Cell culture}

The breast cancer cell line MCF-7 (ATCC ${ }^{\oplus}$ HTB-22 $^{\mathrm{mm}}$ ) were cultured in Dulbecco's Modified Eagle's Medium (DMEM) (ATCC ${ }^{\circ} 30-2002^{\mathrm{m}}$ ) supplemented with 10\% $(v / v)$ fetal bovine serum (FBS, Thermo Scientific, Waltham, MA, USA, Cat No. 12484-020) and 0.4\% ( $v / v)$ gentamicin (Gibco BRL, VWR, Mississauga, ON, CA Cat No. 15710064).

The breast cancer cell line MDA-MB-231 (ATCC HTB-26 $6^{\mathrm{Tm}}$ ) were cultured in Eagle's Minimum Essential Medium (EMEM) (ATCC ${ }^{\ominus} 30-2003^{\text {rw }}$ ) supplemented with $10 \%(\mathrm{v} / \mathrm{v})$ fetal bovine serum $(\mathrm{FBS})$ and $0.4 \%(\mathrm{v} / \mathrm{v})$ gentamicin.

The normal human skin fibroblast cell line (NHF; Coriell Institute for Medical Research, Cat. No. AG09309, Camden, NJ, USA) were cultured in Eagle's Minimum Essential Medium (EMEM) (ATCC ${ }^{\circ} 30-2003^{\mathrm{mm}}$ ) supplemented with $10 \%(\mathrm{v} / \mathrm{v})$ fetal bovine serum (FBS) and $0.4 \%$ (v/v) gentamicin.

All cells were maintained in an incubator at $37^{\circ} \mathrm{C}$ with $5 \% \mathrm{CO}_{2}$ and $95 \%$ humidity. All cells were cultured for less than 6 months with regular passaging.

\section{Analysis of cell death: annexin $\mathrm{V}$ binding assay and propidium iodide}

Annexin $\mathrm{V}$ binding assay and propidium iodide staining were performed to respectively monitor early apoptosis and cell permeabilization, a marker of necrotic or late apoptotic cell death. Cells were treated with various concentrations of hibiscus flower extract similar to those published previously with aqueous extracts of dandelion root and white tea $[18,19]$. Cells were then treated individually or in combination with chemotherapeutics taxol, cisplatin, and tamoxifen as indicated in the results section. This protocol is similar to that previously published $[18,19]$. Cells were washed with phosphate-buffered saline (PBS) and suspended in Annexin V binding buffer (10 mM HEPES, $140 \mathrm{mM} \mathrm{NaCl}, 2.5 \mathrm{mM} \mathrm{CaCl}_{2}, \mathrm{pH}$ 7.4) with green fluorescent Annexin V AlexaFluor-488 (1:20) (Life Technologies Inc., Burlington, ON, CA, Cat No. A13201) and $0.01 \mathrm{mg} / \mathrm{mL}$ of red fluorescent PI (Life Technologies Inc., Burlington, ON, CA, Cat No. P3566) for $15 \mathrm{~min}$ at $37^{\circ} \mathrm{C}$ protected from light. Percentage of early (green), late apoptotic cells (green and red), and necrotic cells (red) were quantified with a Tali Image-Based Cytometer (Life Technologies Inc., Burlington, ON, CA, Cat No. T10796). Cells from at least 18 random fields were analyzed using both the green (ex. $458 \mathrm{~nm}$; em. 525/ $20 \mathrm{~nm}$ ) and red (ex. $530 \mathrm{~nm}$; em. $585 \mathrm{~nm}$ ) channels. Fluorescent micrographs were taken at 400x magnification using LAS AF6000 software with a Leica DMI6000 fluorescent microscope (Wetzlar, Germany). Cells monitored with microscopy were counterstained with Hoechst 33342 (Molecular Probes, Eugene, OR, USA) with a final concentration of $10 \mu \mathrm{M}$ during the 15-min incubation.

\section{Reactive oxygen species (ROS) quantification}

Whole cell ROS generation was monitored with the small molecule 2', 7'-dicholorofluorescin diacetate $\left(\mathrm{H}_{2} \mathrm{DCFDA}\right)$. $\mathrm{H}_{2}$ DCFDA enters the cell and is deacetylated by esterases and oxidized by ROS to the highly fluorescent 2 ', $7^{\prime}$-dicholorofluorescein (DCF) (excitation $495 \mathrm{~nm}$; emission $529 \mathrm{~nm}$ ). This protocol is similar to that previously published [18, 19]. Cells were pretreated with $20 \mu \mathrm{M}$ $\mathrm{H}_{2}$ DCFDA (Sigma-Aldrich Canada, Cat. No. D6883, Mississauga, ON, Canada) for $30 \mathrm{~min}$ at $37^{\circ} \mathrm{C}$ protected from light at $5 \% \mathrm{CO}_{2}$. Cells were treated for the indicated durations, collected, centrifuged at $3500 \times \mathrm{g}$ for $5 \mathrm{~min}$, and resuspended in PBS. Percentage of DCF positive cells was quantified using the Tali Image-Based Cytometer (Life Technologies Inc., Burlington, ON, CA, Cat No. T10796) using 13 random fields per group with the green channel (excitation $458 \mathrm{~nm}$; emission 525/20 nm). Cells were monitored with microscopy and counterstained with Hoechst 33342. Images were taken with a Leica DMI6000 fluorescent microscope (Wetzlar, Germany) at 400x magnification using LAS AF6000 software.

\section{Mitochondrial potential monitoring}

Tetramethylrhodamine methyl ester (TMRM) (Gibco BRL, VWR, Mississauga, ON, CA, Cat No. 89139-392) was used for detecting mitochondrial membrane potential (MMP), an indicator of healthy intact mitochondria. This protocol is similar to that previously published $[18,19]$. Following incubation with TMRM, cells were collected, washed with $1 \mathrm{x}$ PBS, resuspended in PBS, and then analyzed using the Tali Image-Based Cytometer (Life Technologies Inc., Burlington, ON, CA, Cat No. T10796). Cells from 13 random fields were analyzed using the red (ex. $530 \mathrm{~nm}$; em. $585 \mathrm{~nm}$ ) channel. Cells were monitored with microscopy and counterstained with Hoechst 33342. 
Images were taken with a Leica DMI6000 fluorescent microscope (Wetzlar, Germany) at 400x magnification using LAS AF6000 software.

\section{Statistical analysis}

All statistical analysis was done using the GraphPad 6.0 Prism software. To test for statistical significance a two-way analysis of variance (ANOVA) was used. All trials were conducted at least three independent times.

\section{Results}

Hibiscus extract induces apoptosis in a dosage dependent manner in triple-negative and estrogen-receptor positive breast cancer cells

Hot water extract of hibiscus flower was prepared as described in the material and methods. To assess the ability of HE to induce apoptosis in breast cancer, triple-negative and ER+ breast cancer cells were fluorescently stained with apoptosis markers Annexin V (AV) and propidium iodide (PI). The cells were subjected to fluorescent image-based cytometry and fluorescent microscopy following 48- and 96-h treatments.

$\mathrm{HE}$ was effective in inducing apoptosis in both triple-negative MDA-MB-231 and ER+ MCF-7 breast cancer cells (Fig. 1a). Specifically, significant apoptosis induction was observed in both breast cancer cell lines at a dosage of $2 \mathrm{mg} / \mathrm{mL}$ ( $2 \mathrm{mg}$ of crude lyophilized extract in $1 \mathrm{~mL}$ of $\mathrm{ddH}_{2} \mathrm{O}$ ). Dosage dependent apoptosis induction was observed in both cell lines as increasing treatment concentration increased the amount of apoptosis observed.

Both MDA-MB-231 and MCF-7 cells were additionally treated with tamoxifen, taxol, and cisplatin to compare the induction of apoptosis between standard chemotherapeutic treatments and HE. In both cell lines, tamoxifen and cisplatin treatments did not significantly induce apoptosis and taxol significantly induced apoptosis only in MDA-MB-231 cells (Fig. 1a). HE treatment at $4 \mathrm{mg} / \mathrm{mL}$ caused significant induction of apoptosis at a comparable or greater level to all chemotherapeutics tested.

Morphological assays were conducted to assess the effect of treatments on cell morphology. Fluorescent microscopy using AV and PI after hibiscus treatments at $48 \mathrm{~h}$ confirmed apoptosis induction due to hibiscus. These apoptosis markers were observed in MDA-MB-231 breast cancer cells as expected, along with apoptotic morphology including cell shrinkage, membrane blebbing, and nuclear condensation (Fig. 1b).

\section{Interaction of hibiscus extract with conventional chemotherapies tamoxifen, taxol, and cisplatin in combination treatments}

Commonly today, many chemotherapeutics are utilized in conjunction with other drugs. In order to assess if $\mathrm{HE}$ can be combined with chemotherapeutics in a novel treatment regimen, combination assays were conducted to determine whether or not hibiscus enhances, inhibits, or has no effect on chemotherapeutic potency. MDA-MB-231 and MCF-7 breast cancer cells were treated with tamoxifen, taxol, and cisplatin in the presence or absence $1 \mathrm{mg} / \mathrm{mL}$ HE. As described above, both image-based cytometry and fluorescent microscopy were used to analyze apoptosis induction.

In the triple-negative breast cancer cell line, MDAMB-231, combination treatments of chemotherapeutics taxol and cisplatin with $1 \mathrm{mg} / \mathrm{mL}$ HE were able to significantly increase the induction of apoptosis when compared to chemotherapeutic treatments alone (Fig. 2a). Interestingly, the lowest combination concentration of taxol treatment $(0.01 \mu \mathrm{M}$ with $1 \mathrm{mg} / \mathrm{mL} \mathrm{HE})$ showed similar apoptosis induction to the highest individual treatment concentration of taxol $(0.5 \mu \mathrm{M})$. This indicates that combination treatment with $1 \mathrm{mg} / \mathrm{mL} \mathrm{HE}$ was able to show a similar apoptosis induction to individual treatment with a 50-fold decrease in chemotherapeutic concentration. Using fluorescent microscopy, this result was confirmed with combination treatments of taxol and cisplatin along with HE showing a higher incidence of apoptotic marker fluorescence and increased apoptotic morphology when compared to individual chemotherapeutic treatments (Fig. 2b).

In ER+ breast cancer cell line, MCF-7, combination treatments of chemotherapeutics tamoxifen, taxol and cisplatin with $1 \mathrm{mg} / \mathrm{mL} \mathrm{HE}$ did not show any significant change in apoptosis induction when compared to individual treatments (Fig. 3a). Although we did not observe any enhancement, there was no inhibition observed. This result was confirmed using fluorescent microscopy (Fig. 3b). However, it is important to note that the chemotherapeutic treatment ranges used did not show any significant apoptosis induction in MCF-7. As shown in Fig. $1, \mathrm{HE}$ at a concentration of $2 \mathrm{mg} / \mathrm{mL}$ showed significant apoptosis induction while combination treatments with $1 \mathrm{mg} / \mathrm{mL}$ did not induce significant apoptosis.

\section{Hibiscus extract is selective in inducing apoptosis for breast cancer cells}

If selective for breast cancer, individual and combinatory HE treatment could potentially minimize adverse side effects by not affecting healthy cells. In order to investigate the selectivity of $\mathrm{HE}$ for breast cancer, normal human fibroblast (NHF) cells were treated with HE treatments and assessed in a similar manner as described above. Compared to control treatments, there was no increase in apoptosis in $\mathrm{HE}$ up to $2 \mathrm{mg} / \mathrm{mL}$ at which we have observed significant apoptosis in cancer cells (Fig. 1). There was minimal to no observable apoptosis induction when compared to the positive control 


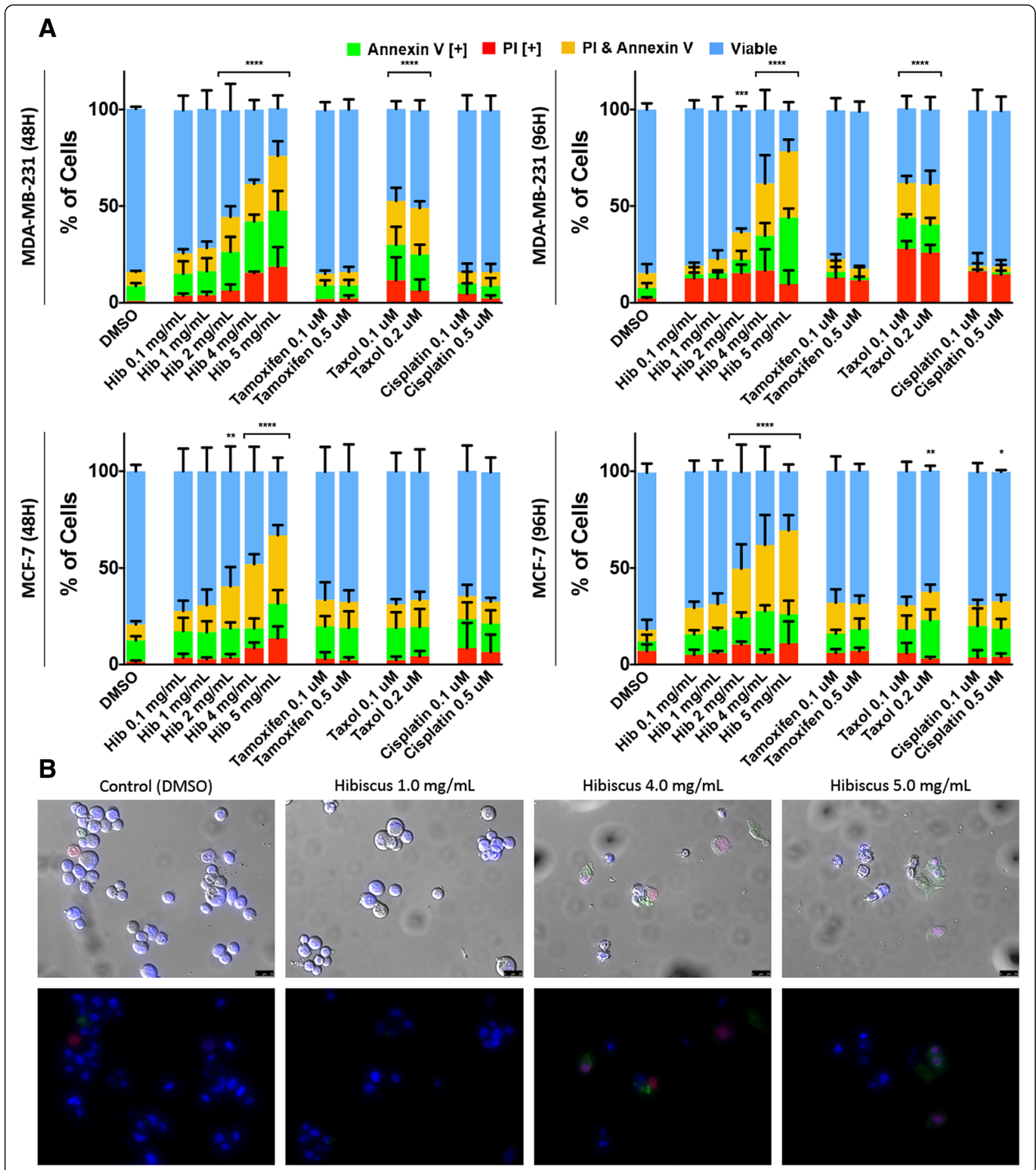

Fig. 1 Hibiscus extracts induce apoptosis in breast cancer. a Breast cancer cell lines MDA-MB-231 and MCF-7 were treated with various treatments of $\mathrm{HE}$ and chemotherapeutics and assessed at $48 \mathrm{~h}$ and $96 \mathrm{~h}$. Results were obtained using image-based cytometry to assess the percentage of cells positive with fluorescence associated with Annexin V (green), PI (red), both (yellow), or negative for both Annexin V and PI (blue). Values are expressed as a mean \pm SD from three independent experiments. b Fluorescence microscopy images of 1.0, $4.0 \mathrm{and} 5.0 \mathrm{mg} / \mathrm{mL}$ HE treatment on MDA-MB-231 cells were taken at $48 \mathrm{~h}$. Top panels: Brightfield and fluorescent merged images at 400x magnification. Bottom: Fluorescent images stained with Annexin V (green), PI (red), and Hoechst (blue) at 400x magnification. Scale bar is $50 \mu \mathrm{m}$. Images are representative of three independent experiments. Statistical calculations were performed using Two-Way ANOVA multiple comparison. ${ }^{*} p<0.05$ vs. Control, ${ }^{* *} p<0.01$ vs. Control, ${ }^{* * *} p<0.0001$ vs. Control 


\section{A}

Annexin V [+] $\square \mathrm{PI}[+] \square \mathrm{PI}$ \& Annexin V Viable
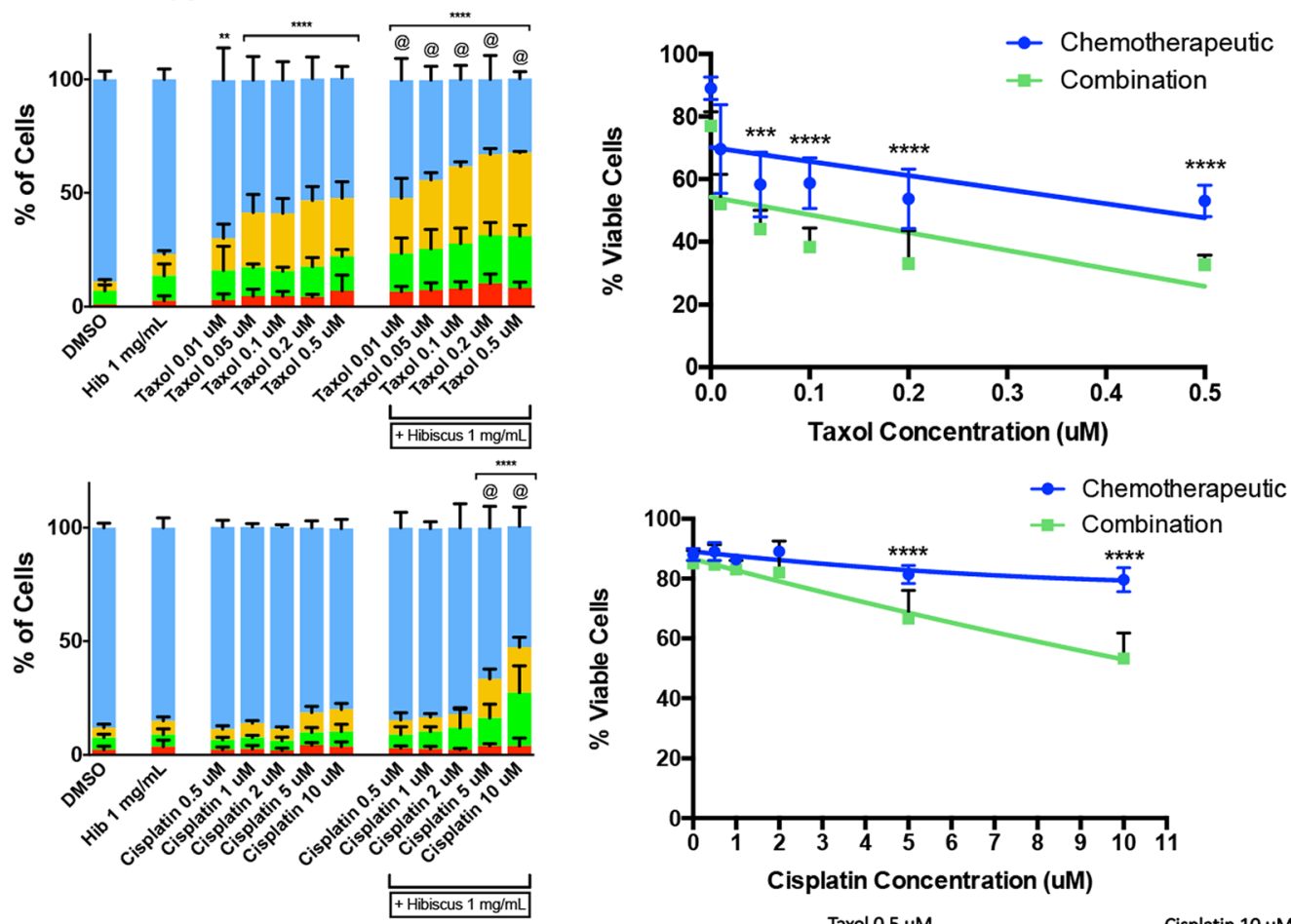

B
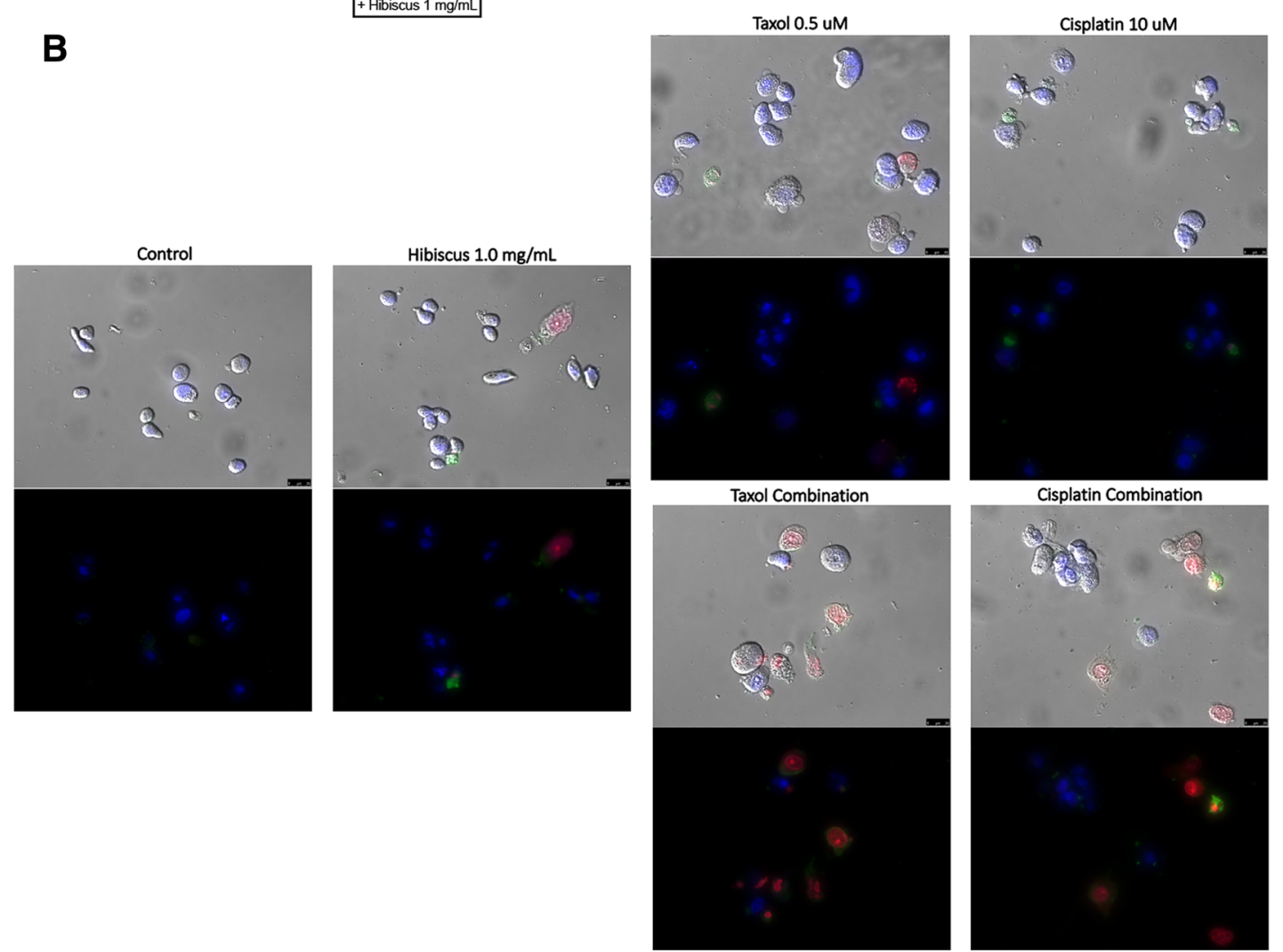

Cisplatin Combination

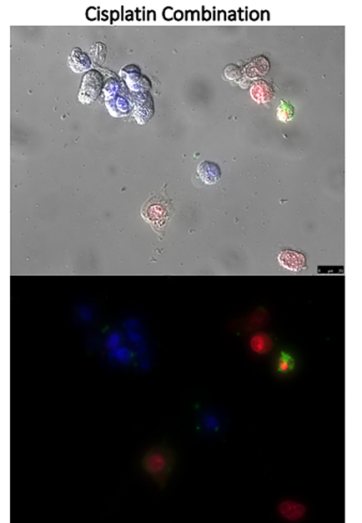

Fig. 2 (See legend on next page.) 
(See figure on previous page.)

Fig. 2 Hibiscus extracts indicate synergy with chemotherapeutics when treated in combination on triple-negative breast cancer cells. a MDA-MB231 cells were treated with chemotherapeutics taxol (top panel) and cisplatin (bottom panel) individually and in combination with $1 \mathrm{mg} / \mathrm{mL} \mathrm{HE}$ and assessed at $48 \mathrm{~h}$. Results were obtained using image-based cytometry to assess the percentage of cells positive with fluorescence associated with Annexin V (green), PI (red), both (yellow), or negative for both Annexin $V$ and PI (blue). Values are expressed as a mean \pm SD from three independent experiments. The percentage of viable cells were graphed for both individual chemotherapeutic and combination chemotherapeutic treatments (graphs on right). $\mathbf{b}$ Fluorescence microscopy images of individual and hibiscus combination chemotherapeutic treatments on MDA-MB231 cells were taken at $48 \mathrm{~h}$.. Top panels: Brightfield and fluorescent merged images at 400x magnification. Bottom: Fluorescent images stained with Annexin V (green), PI (red), and Hoechst (blue) at 400x magnification. Scale bar is $50 \mu \mathrm{m}$. Images are representative of three independent experiments. Statistical calculations were performed using Two-Way ANOVA multiple comparison. ${ }^{*} p<0.05$ vs. Control, ${ }^{* *} p<0.01$ vs. Control, ${ }^{* * * *} p<0.0001$ vs. Control, @p $<0.05$ vs. Individual Chemotherapy Treatment

taxol (at a high dosage known to be cytotoxic to normal human cells) using HE treatments that were highly efficacious when used to treat breast cancer cells (Fig. 4a). These results were confirmed with fluorescent microscopy. Cells only began to show apoptotic marker fluorescence and apoptotic morphology at the highest $\mathrm{HE}$ concentration of $5 \mathrm{mg} / \mathrm{mL}$ (Fig. 4c).

To further investigate the benefit of using a combination treatment of $\mathrm{HE}$ with chemotherapeutics, taxol and hibiscus combination treatments were compared to individual treatments of taxol on NHF cells. On their own, chemotherapeutics treatments showed toxicity (Fig. 4b). They are non-selective compared to hibiscus. Most surprisingly, HE combination treatments did not lead to increased apoptosis induction when compared to individual treatments, but instead lowered the amount of apoptosis induction observed (Fig. 4b). These results indicate that HE shows selectivity to breast cancer cells and potentially protects normal human healthy cells from being affected by chemotherapeutic treatments.

\section{Hibiscus extract is able to induce apoptosis in breast cancer cells by increasing oxidative stress and targeting the mitochondria}

$\mathrm{HE}$ is an extract composed of many compounds able to interact in a complex manner. Determining the method of apoptosis induction will allow for a greater understanding of how these complex extracts show the observed anticancer potency. In order to determine if $\mathrm{HE}$ is able to induce apoptosis in breast cancer through inducing oxidative stress, $\mathrm{H}_{2}$ DCFDA was used to monitor the generation of ROS in breast cancer cells treated with chemotherapeutics in the presence or absence of HE. Indeed, it was observed that individual HE treatment was able to induce significant ROS generation in treated cells (Fig. 5a). Further, combination treatments on triple-negative MDA-MB-231 cells using chemotherapeutic and HE were able to significantly increase the generation of ROS in treated cells when compared to treatment in the absence of HE. These results were confirmed using fluorescence microscopy (Fig. 5b).

Further, as HE is made up of multiple factors and components, some of these may also target the mitochondria. Tetramethylrhodamine methyl ester (TMRM) dye was used in order to visualize the mitochondria membrane potential (MMP) in treated cells. Interestingly, $\mathrm{HE}$ at $1 \mathrm{mg} / \mathrm{mL}$ did not show significant loss of the MMP but instead was able to amplify the loss of MMP in both triple-negative and ER+ breast cancer cells when present in chemotherapeutic treatment compared to when absent (Fig. 6a). These results were confirmed using fluorescent microscopy (Fig. 6b).

\section{Discussion}

In this study, we have shown that HE is able to induce apoptosis in both human ER+ and triple-negative breast cancer cell lines in vitro (Fig. 2a). We have demonstrated that $\mathrm{HE}$ treatment is very selective in inducing cell death in cancer cells without any significant effect on NHF cells (Fig. 4a). On the other hand, common chemotherapeutics like taxol were indiscriminate and induced apoptosis in both cancer and non-cancerous cells (Fig. 4a). Most importantly, we have shown that addition of HE in combination with chemotherapeutic agents enhanced the induction of apoptosis in triple-negative breast cancer cells (Fig. 2a). These results support the possibility of supplementing chemotherapeutic regimens with HE, which is well-tolerated in normal healthy cells. This may lead to a better combined effect, reducing the chemotherapeutic dosages needed in treatment and therefore reduce toxicity.

As indicated previously, breast cancer, primarily triple-negative, is highly resistant to chemotherapy treatment. We have shown that both triple-negative and ER-positive breast cancer cells are affected by HE treatment (Fig. 2). HE has also been shown to induce apoptosis significantly around treatment of $2 \mathrm{mg} / \mathrm{mL}$ of crude extract in prostate cancer, with a similar dose-dependency [24].

A common hesitation of using natural health product extracts alongside chemotherapies is the possibility of negative drug interactions, leading to reduced efficacy in treatment. Our goal was to investigate whether or not combination HE treatments would inhibit, not affect, or enhance the efficacy of chemotherapeutic treatments. Indeed, we found that taxol and cisplatin treatments on triple-negative breast cancer cells were enhanced with the addition of $1 \mathrm{mg} / \mathrm{mL}$ (sublethal dosage in individual 
A
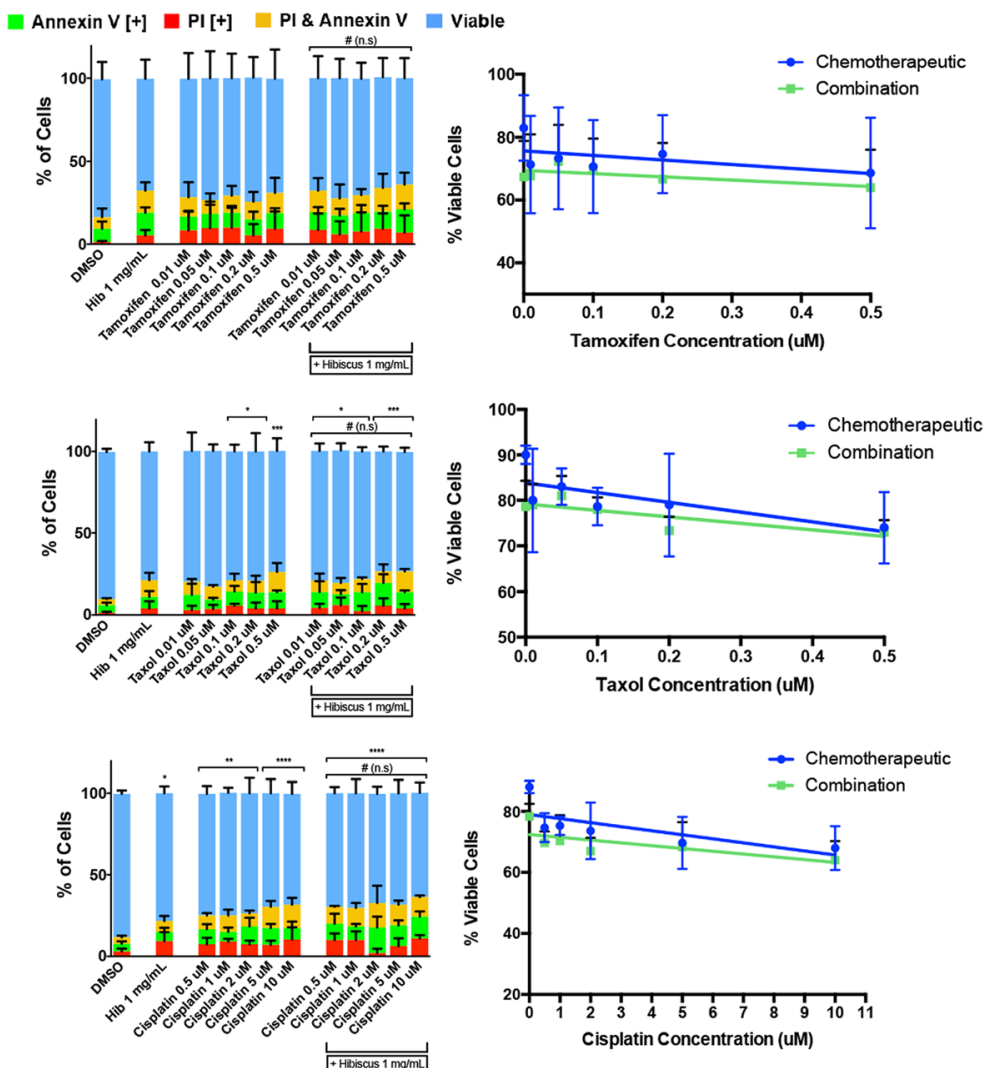

B
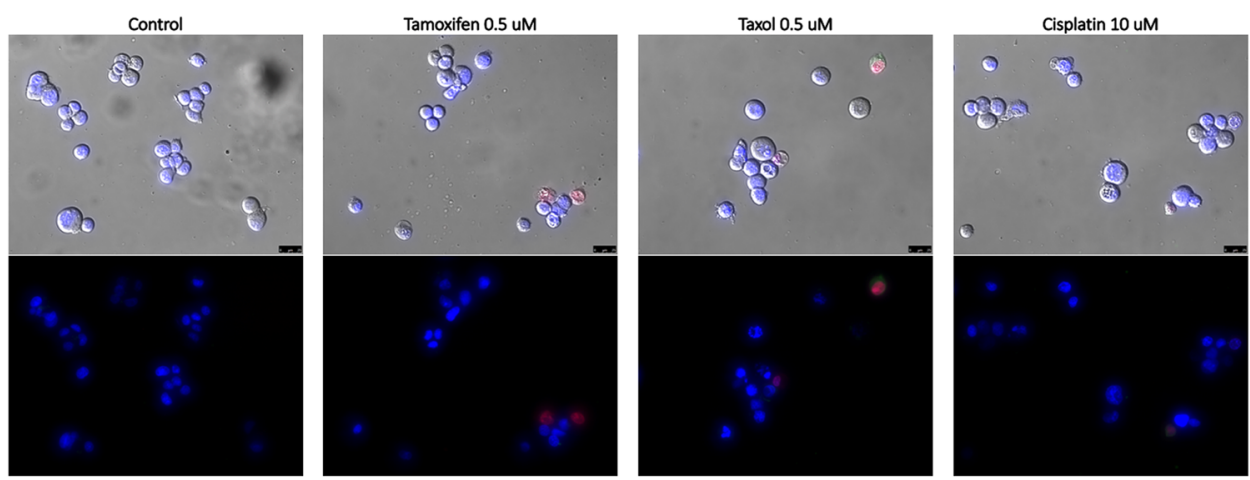

Hibiscus $1.0 \mathrm{mg} / \mathrm{mL}$

Tamoxifen Combination

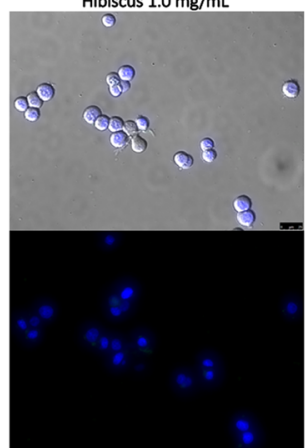

Taxol Combination
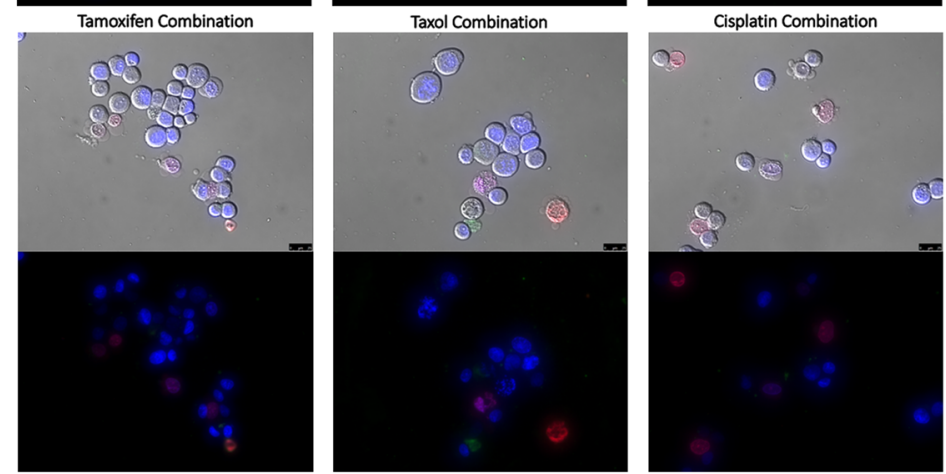

Fig. 3 (See legend on next page.) 
(See figure on previous page.)

Fig. 3 Hibiscus extracts do not interact with chemotherapeutics in combination treatment on estrogen-receptor positive breast cancer. a MCF-7 cells were treated with chemotherapeutics tamoxifen (top panel, taxol (middle panel), and cisplatin (bottom panel) individually and in combination with $1 \mathrm{mg} / \mathrm{mL} \mathrm{HE}$ and assessed at $48 \mathrm{~h}$. Results were obtained using image-based cytometry to assess the percentage of cells positive with fluorescence associated with Annexin V (green), PI (red), both (yellow), or negative for both Annexin $V$ and PI (blue). Values are expressed as a mean \pm SD from three independent experiments. The percentage of viable cells were graphed for both individual chemotherapeutic and combination chemotherapeutic treatments (graphs on right). b Fluorescence microscopy images of individual and hibiscus combination chemotherapeutic treatments on MDA-MB-231 cells were taken at 48 h.. Top panels: Brightfield and fluorescent merged images at 400x magnification. Bottom: Fluorescent images stained with Annexin $V$ (green), PI (red), and Hoechst (blue) at 400x magnification. Scale bar is $50 \mu \mathrm{m}$. Images are representative of three independent experiments. Statistical calculations were performed using Two-Way ANOVA multiple comparison. ${ }^{*} p<0.05$ vs. Control, ${ }^{* *} p<0.01$ vs. Control, ${ }^{* * *} p<0.0001$ vs. Control, @p $<0.05$ vs. Individual Chemotherapy Treatment, \#= not significant vs. Individual Chemotherapy Treatment

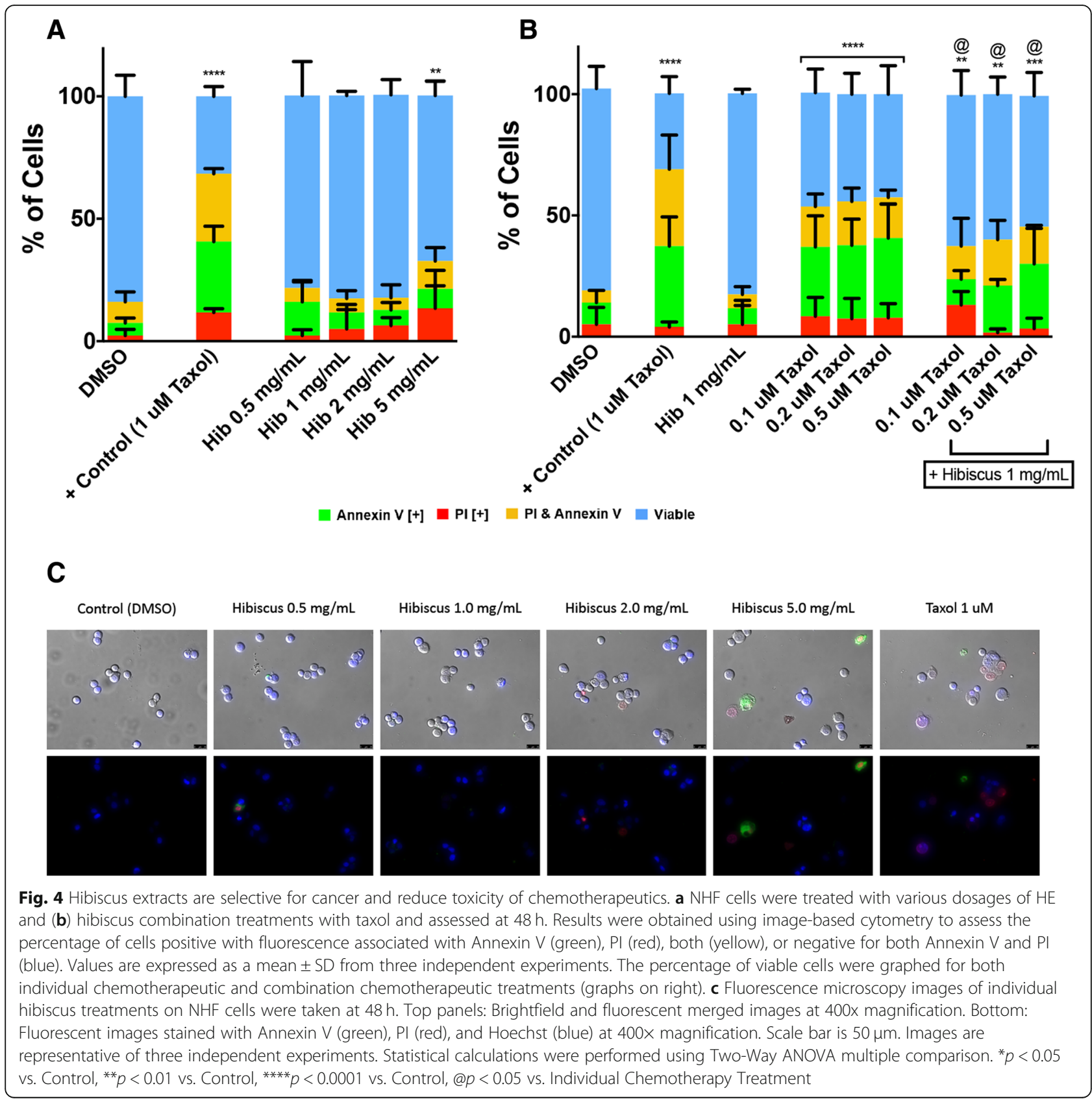




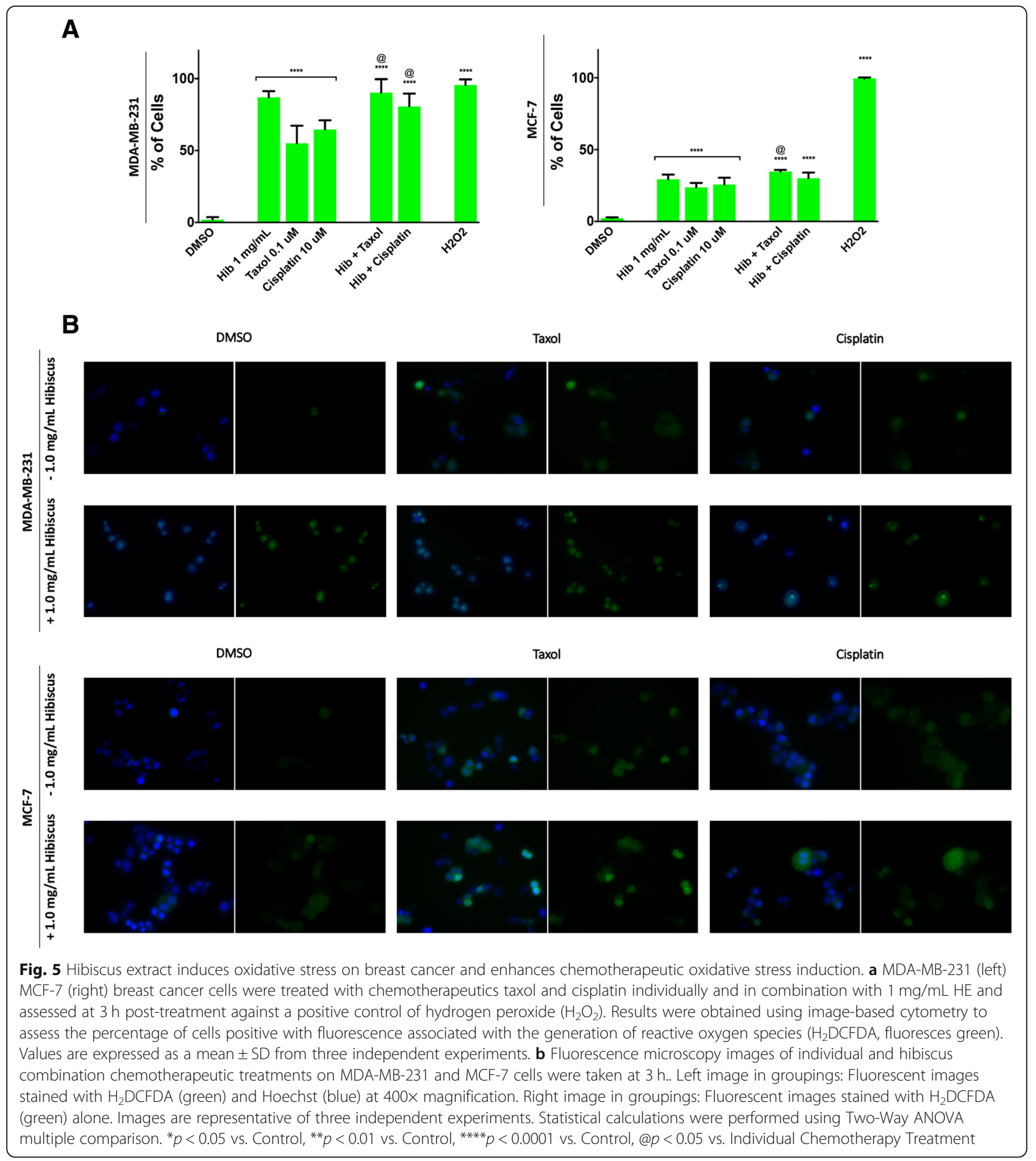

treatment) HE treatment (Fig. 2) while unaffected in ER-positive breast cancer cells. These results clearly indicate that HE's interaction with chemotherapeutic drugs is positive or has no interaction in breast cancer cells. If any effect was observed at all, HE treatment enhanced the efficacy of chemotherapeutic treatments. Moreover,
HE combination treatments on NHF cells were able to reduce the toxicity of taxol (Fig. 4a). Extent of apoptosis induced by $0.01 \mu \mathrm{M}$ taxol in combination with $\mathrm{HE}$ was equivalent to that induced by $0.5 \mu \mathrm{M}$ taxol alone (Fig. 2a). This 50-fold decrease in effective chemotherapy concentration clearly indicates the possibility of reducing 


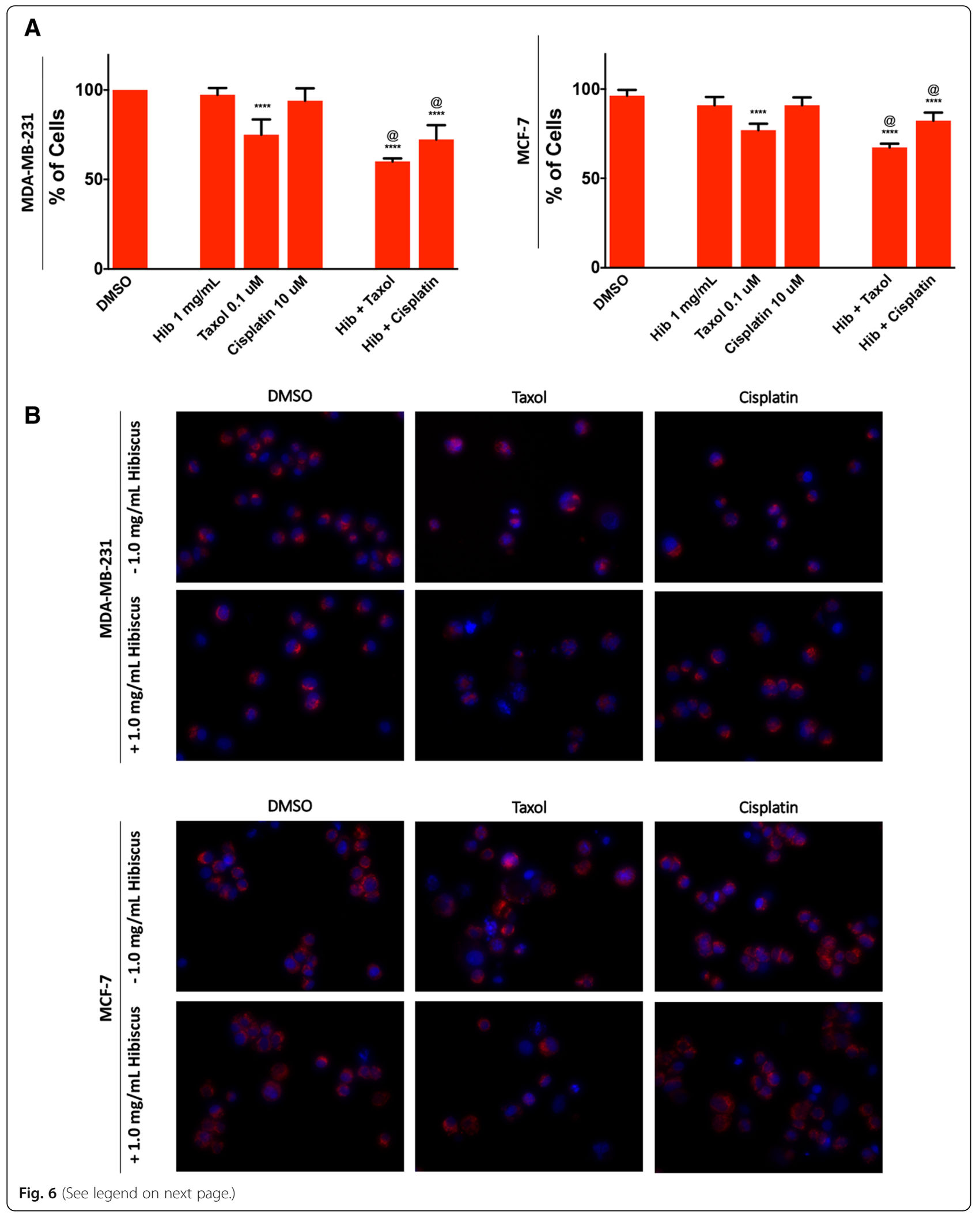


(See figure on previous page.)

Fig. 6 Hibiscus extract enhances chemotherapeutic ability to reduce mitochondrial membrane potential. a MDA-MB-231 (left) MCF-7 (right) breast cancer cells were treated with chemotherapeutics taxol and cisplatin individually and in combination with $1 \mathrm{mg} / \mathrm{mL}$ HE and assessed at 48 h. Results were obtained using image-based cytometry to assess the percentage of cells positive with fluorescence associated with mitochondrial membrane potential (TMRM, fluoresces red). Values are expressed as a mean \pm SD from three independent experiments. b Fluorescence microscopy images of individual and hibiscus combination chemotherapeutic treatments on MDA-MB-231 and MCF-7 cells were taken at $48 \mathrm{~h}$.. Fluorescent images stained with TMRM (red) and Hoechst (blue) at 400x magnification. Images are representative of three independent experiments. Statistical calculations were performed using Two-Way ANOVA multiple comparison. ${ }^{*} p<0.05$ vs. Control, ${ }^{* *} p<0.01$ vs. Control, ${ }^{* * * *} p<0.0001$ vs. Control, @p<0.05 vs. Individual Chemotherapy Treatment

chemotherapeutic dosage to avoid adverse side-effects without sacrificing efficacy. As such, HE could serve a significant purpose in terms of adjuvant therapy.

The mechanism of apoptosis induction in breast cancer is a topic of great interest to determine the underlying cause of cell death. Previously, we have shown that ethanolic extracts of lemongrass and aqueous extracts of dandelion root were able to induce oxidative stress and decrease mitochondrial membrane potential, leading to apoptosis induction in cancer cells $[18,19]$. While the exact mechanism is not yet clear, it has been hypothesized that high ROS levels can activate cellular stress mechanisms and may sensitize cancer cells to further ROS production leading to apoptosis [9]. Indeed, our results indicate that $\mathrm{HE}$ treatment led to increased ROS generation in both triple-negative and ER + breast cancer cells (Fig. 5). Moreover, taxol and cisplatin treatments in combination with HE showed increased ROS generation when compared to individual treatments. This helps explain the increase in apoptosis induction of combination treatments compared to individual treatments as discussed above (Figs. 3, 4). It should be noted that triple-negative breast cancer cells were more vulnerable to oxidative stress than ER-positive breast cancer cells. These are two different cells with varied susceptibilities, and the lowered ROS generation of ER-positive breast cancer treatment indicates either an alternate mechanism of apoptosis induction or a need for increased dosage. Further, we have demonstrated that $\mathrm{HE}$ combination treatment is able to enhance the mitochondrial membrane potential reduction in breast cancer cells (Fig. 6).

As indicated above, cisplatin and taxol have shown extremely toxic side effects due to a lack of selectivity in treatment. Studies have indicated that HE is well-tolerated in nude mice xenograft models while exhibiting an anti-metastatic and anti-tumour effect [24]. Hibiscus has been traditionally used and has shown to be well-tolerated when consumed by humans. Consumption has also been associated with many beneficial effects including supporting mitochondrial function, energy homeostasis and improvement of the cardiovascular health [32]. Indeed, we have shown that HE was selectively toxic to cancer cells wherein the lowest effective dose of HE on breast cancer
( $2 \mathrm{mg} / \mathrm{mL}$ ) was unable affect NHF cells (Fig. 4a). HE treatments in combination with chemotherapeutics were also able to reduce the toxicity in NHF cells and lower the amount of apoptosis induction when compared to chemotherapeutic treatments in the absence of HE (Fig. 4b). As such, HE shows great potential as an adjuvant to these therapies and help render some selectivity in treatment for cancer. If HE treatment shows anticancer efficacy, it could be used over a long-term period of time without any side effects [33].

It is important to note that HE dosages may appear to be high compared to pure compound cancer therapeutics. However, it is important to note that this is an aqueous extract of the hibiscus flower, which contains mainly sugars, salts, and other naturally abundant compounds in flowers. Previous work on phytochemical analysis of many other extracts including long pepper (Piper longum) and dandelion root (Taraxacum officinale) have shown that the concentration of the active compound might be very low $[18,20]$. Further, our work on these NHPs showed that active compounds found in long pepper and dandelion root extract were ineffective in apoptosis induction when used alone [20]. This indicates the importance of multiple phytochemicals that work together natural extracts. In this case, it represents a very interesting opportunity for further research into $\mathrm{HE}$ to identify and test the potency of active compounds in aqueous hibiscus flower extract.

\section{Conclusions}

The work presented in this study indicates great potential of NHPs such HE to treat breast cancer in combination with standard chemotherapies. HE has shown an ability to enhance apoptotic induction by chemotherapy treatments through an increase in ROS generation and mitochondrial membrane collapse on both triple-negative and ER-positive breast cancer cells. This result is significant due to the general difficulty in discovery of an effective treatment for resistant triple-negative breast cancer. Most importantly, addition of $\mathrm{HE}$ with chemotherapeutic treatment could produce desired level of apoptotic induction at very low dosages of chemotherapies compared to chemotherapies alone. Therefore, addition of HE can significantly reduce the drug-related toxicity of chemotherapeutics. Future work 
into assessment of $\mathrm{HE}$ can look into combinatorial effects on in vivo models to further investigate the potential of $\mathrm{HE}$ for human usage. We have shown that HE treatment has the potential to be used alongside tamoxifen, taxol, and cisplatin treatments without any inhibition of drug potency. Thus, these findings open up interesting opportunity for further development of NHPs as a promising anticancer treatment option.

\section{Abbreviations}

AV: Annexin V; DCF: 2', 7'-dicholorofluorescein; $\mathrm{dd} \mathrm{H}_{2} \mathrm{O}$ : Double distilled water; DMSO: Dimethyl sulfoxide; ER+: Estrogen-receptor positive; $\mathrm{H}_{2}$ DCFDA: 2', 7'dicholorofluorescin diacetate; HE: Hibiscus extract; MMP: Mitochondria membrane potential; NHF: Normal human fibroblast; NHP: Natural health product; PBS: Phosphate buffer saline; PI: Propidium iodide; ROS: Reactive oxygen species; TMRM: Tetramethylrhodamine methyl ester

\section{Acknowledgements}

The authors would all like to acknowledge the rest of our cancer group members (Krishan, Johan, Chris, Rahul, Siddh, Lauren, Kyle, and Jana) as well as the rest of our research group for their assistance and feedback on the work presented.

The authors would also like to acknowledge all past members of Dr. Pandey's research lab for their contributions to the Natural Health Products project. Specifically, CN would like to thank Dennis Ma and Christopher Pignanelli for their help and advice at various stages of the project.

\section{Funding}

The authors are grateful to the Rasch Foundation, the Lotte and John Hecht Foundation, and the Couvillon family for their support for this project. These supports were for the design and execution of the experiment and writing and publication of these results.

\section{Availability of data and materials}

The datasets used and/or analysed during the current study are available from the corresponding author on reasonable request.

\section{Authors' contributions}

CN co-conducted all experiments with the help from all other authors and was the major contributor in analyzing data, preparing figures and writing the manuscript. KB co-conducted all apoptotic induction assays along with $\mathrm{CN}, \mathrm{AP}$, and $\mathrm{OZ}$ and was a contributor in writing the manuscript. AP assisted with apoptotic induction assays and cell culturing. IR co-conducted mechanistic (reactive oxidation species generation and mitochondrial membrane potential) assays. OZ assisted with apoptotic induction assays and fluorescent microscopy pictures. SG, BS, and AM assisted with cell culturing and various assays where applicable. CV assisted with fluorescent microscopy and apoptotic induction experiments. SP is the primary investigator of this experiment All authors read and approved the final manuscript.

\section{Ethical approval and consent to participate}

Not applicable

\section{Consent for publication}

Not applicable

\section{Competing interests}

The authors declare that they have no competing interests.

\section{Publisher's Note}

Springer Nature remains neutral with regard to jurisdictional claims in published maps and institutional affiliations.
Received: 17 January 2019 Accepted: 16 April 2019

Published online: 06 May 2019

\section{References}

1. Torre LA, Bray F, Siegel RL, Ferlay J, Lortet-Tieulent J, Jemal A. Global cancer statistics, 2012. CA Cancer J Clin. 2015;65(2):87-108. https://doi.org/10.3322/ caac. 21262

2. Shah R, Rosso K, Nathanson SD. Pathogenesis, prevention, diagnosis and treatment of breast cancer. World J Clin Oncol. 2014:5(3):283-98.

3. Tyrer J, Duffy SW, Cuzick J. A breast cancer prediction model incorporating familial and personal risk factors. Stat Med. 2004;23(7):1111-30.

4. Warner E, Messersmith $H$, Causer $P$, Eisen A, Shumak R, Plewes D. Systematic review: using magnetic resonance imaging to screen women at high risk for breast cancer. Ann Intern Med. 2008;148(9):671-9.

5. Nelson HD, Tyne K, Naik A, et al. Screening for breast cancer: an update for the U.S. preventive services task force. Ann Intern Med. 2009;151(10):727-37 W237-42.

6. Fitzgibbons PL, Page DL, Weaver D, Thor AD, Allred DC, Clark GM, Ruby SG, O'Malley F, Simpson JF, Connolly JL, Hayes DF, Edge SB, Lichter A, Schnitt SJ. Prognostic factors in breast cancer. College of American Pathologists Consensus Statement 1999. Arch Pathol Lab Med. 2000;124(7):966-78.

7. Weigelt B, Peterse JL, van 't Veer LJ. Breast cancer metastasis: markers and models. Nat Rev Cancer. 2005;5(8):591-602.

8. Wong RS. Apoptosis in cancer: from pathogenesis to treatment. J Exp Clin Cancer Res. 2011;30:87. https://doi.org/10.1186/1756-9966-30-87.

9. Panieri E, Santoro MM. ROS homeostasis and metabolism: a dangerous liason in cancer cells. Cell Death Dis. 2016;7(6):e2253. Published 2016 Jun 9. https://doi.org/10.1038/cddis.2016.105.

10. Wang C, Youle RJ. The role of mitochondria in apoptosis. Annu Rev Genet. 2009:43:95-118.

11. Zasadil LM, Andersen KA, Yeum D, et al. Cytotoxicity of paclitaxel in breast cancer is due to chromosome missegregation on multipolar spindles. Sci Transl Med. 2014;6(229):229ra43.

12. Dasari S, Tchounwou PB. Cisplatin in cancer therapy: molecular mechanisms of action. Eur J Pharmacol. 2014;740:364-78.

13. Nounou MI, ElAmrawy F, Ahmed N, Abdelraouf K, Goda S, Syed-Sha-Qhattal $\mathrm{H}$. Breast Cancer: conventional diagnosis and treatment modalities and recent patents and technologies. Breast Cancer (Auckl). 2015;9(Suppl 2):17-34. Published 2015 Sep 27. https:/doi.org/10.4137/BCBCR.S29420.

14. Liedtke C, Mazouni C, Hess KR, André F, Tordai A, Mejia JA, Symmans WF, Gonzalez-Angulo AM, Hennessy B, Green M, Cristofanilli M, Hortobagyi GN, Pusztai L. Response to neoadjuvant therapy and long-term survival in patients with triple-negative breast cancer. J Clin Oncol. 2008;26(8):1275-81. https://doi.org/10.1200/JCO.2007.14.4147.

15. Carey LA, Dees EC, Sawyer L, Gatti L, Moore DT, Collichio F, Ollila DW, Sartor $\mathrm{Cl}$, Graham ML, Perou CM. The triple negative paradox: primary tumor chemosensitivity of breast cancer subtypes. Clin Cancer Res. 2007;13(8): 2329-34.

16. Trottier G, Boström PJ, Lawrentschuk N, Fleshner NE. Nutraceuticals and prostate cancer prevention: a current review. Nat Rev Urol. 2010;7(1):21-30. https://doi.org/10.1038/nrurol.2009.234

17. Weaver B. How Taxol/paclitaxel kills cancer cells. Mol Biol Cell. 2014;25(18): 2677-81.

18. Ovadje P, Ammar S, Guerrero JA, Arnason JT, Pandey S. Dandelion root extract affects colorectal cancer proliferation and survival through the activation of multiple death signalling pathways. Oncotarget. 2016;7(45): 73080-100

19. Philion C, Ma D, Ruvinov I, et al. Cymbopogon citratus and Camellia sinensis extracts selectively induce apoptosis in cancer cells and reduce growth of lymphoma xenografts in vivo. Oncotarget. 2017;8(67):110756-73. Published 2017 Nov 18. https://doi.org/10.18632/oncotarget.22502.

20. Ovadje $P, M a D$, Tremblay $P$, et al. Evaluation of the efficacy \& biochemical mechanism of cell death induction by Piper longum extract selectively in invitro and in-vivo models of human cancer cells. PLoS One. 2014;9(11):e113250. Published 2014 Nov 17. https://doi.org/10.1371/journal.pone.0113250.

21. Ovadje P, Roma A, Steckle M, Nicoletti L, Arnason JT, Pandey S. Advances in the research and development of natural health products as main stream cancer therapeutics. Evid Based Complement Alternat Med. 2015;2015: 751348.

22. Haji Faraji M, Haji Tarkhani A. The effect of sour tea (Hibiscus sabdariffa) on essential hypertension. J Ethnopharmacol. 1999;65(3):231-6. 
23. Ochani PC, D'Mello P. Antioxidant and antihyperlipidemic activity of Hibiscus sabdariffa Linn. Leaves and calyces extracts in rats. Indian J Exp Biol. 2009;47(4):276-82.

24. Chiu CT, Chen JH, Chou FP, Lin HH. Hibiscus sabdariffa leaf extract inhibits human prostate Cancer cell invasion via Down-regulation of Akt/NF-kB/ MMP-9 pathway. Nutrients. 2015;7(7):5065-87. Published 2015 Jun 24. https://doi.org/10.3390/nu7075065.

25. Tseng TH, Kao TW, Chu CY, Chou FP, Lin WL, Wang CJ. Induction of apoptosis by hibiscus protocatechuic acid in human leukemia cells via reduction of retinoblastoma (RB) phosphorylation and $\mathrm{BCl}-2$ expression. Biochem Pharmacol. 2000;60(3):307-15.

26. Lin HH, Chen JH, Kuo WH, Wang CJ. Chemopreventive properties of Hibiscus sabdariffa L. on human gastric carcinoma cells through apoptosis induction and JNK/P38 MAPK signaling activation. Chem Biol Interact. 2007;165(1):59-75.

27. Malacrida A, Maggioni D, Cassetti A, Nicolini G, Cavaletti G, Miloso M. Antitumoral effect of Hibiscus sabdariffa on human squamous cell carcinoma and multiple myeloma cells. Nutr Cancer. 2016;68(7):1161-70. https://doi.org/10.1080/01635581.2016.1208830.

28. Hsu RJ, Hsu YC, Chen SP, Fu CL, Yu JC, Chang FW, Chen YH, Liu JM, Ho JY, Yu CP. The triterpenoids of Hibiscus syriacus induce apoptosis and inhibit cell migration in breast cancer cells. BMC Complement Altern Med. 2015;15: 65. https://doi.org/10.1186/s12906-015-0592-9.

29. Anders C, Carey LA. Understanding and treating triple-negative breast cancer. Oncology (Williston Park). 2008;22(11):1233-9 discussion 1239-40, 1243.

30. Collignon J, Lousberg L, Schroeder H, Jerusalem G. Triple-negative breast cancer: treatment challenges and solutions. Breast Cancer (Dove Med Press). 2016;8:93-107. Published 2016 May 20. https://doi.org/10.2147/BCTT.S69488.

31. Yao H, He G, Yan S, et al. Triple-negative breast cancer: is there a treatment on the horizon? Oncotarget. 2016;8(1):1913-24.

32. Beltrán-Debón R, Rodríguez-Gallego E, Fernández-Arroyo S, Senan-Campos $\mathrm{O}$, Massucci FA, Hernández-Aguilera A, Sales-Pardo M, Guimerà R, Camps J, Menendez JA, Joven J. The acute impact of polyphenols from Hibiscus sabdariffa in metabolic homeostasis: an approach combining metabolomics and gene-expression analyses. Food Funct. 2015;6(9):2957-66. https://doi.org/10.1039/c5fo00696a.

33. Herranz-López M, Olivares-Vicente M, Encinar JA, et al. Multi-targeted molecular effects of Hibiscus sabdariffa polyphenols: an opportunity for a global approach to obesity. Nutrients. 2017;9(8):907. Published 2017 Aug 20. https://doi.org/10.3390/nu9080907.

Ready to submit your research? Choose BMC and benefit from:

- fast, convenient online submission

- thorough peer review by experienced researchers in your field

- rapid publication on acceptance

- support for research data, including large and complex data types

- gold Open Access which fosters wider collaboration and increased citations

- maximum visibility for your research: over $100 \mathrm{M}$ website views per year

At BMC, research is always in progress.

Learn more biomedcentral.com/submissions 